\title{
MODEL MATEMATIKA ALIRAN KONVEKSI BEBAS FLUIDA VISKOELASTIK YANG MELEWATI SILINDER ELIPTIK DENGAN PENGARUH MAGNETOHYDRODYNAMICS (MHD)
}

\author{
Annisa Dwi Sulistyaningtyas \\ Fakultas Keguruan dan Ilmu Pendidikan, Universitas PGRI Adi Buana Surabaya \\ annisadwistyas@unipasby.ac.id
}

\begin{abstract}
In fluid case, the mathematical model is the basic for translating a problem into a mathematical language using an equation or function. The governing equation is developed from continuity equation, momentum equation, and energy equation. Fluid characteristics are viscous and elastic result in boundary layer on the surface of elliptic cylinder. Dimensional equations are transformed into non-dimensional form and then classified into the similarity equations using boundary layer theory with influence of magnetic force. The results of this research is mathematical model of free convection flow in viscoelastic fluid passing through the elliptic cylinder with magnetohydrodinamics (MHD). For variation of magnetohydrodinamics (MHD) parameter, velocity and temperature increase when the parameter increases.
\end{abstract}

Keywords: Mathematical modelling, free convection, elliptic cylinder, Magnetohydrodinamics (MHD)

\section{PENDAhuluan}

Pada studi kasus di bidang fluida, model matematika merupakan dasar untuk menerjemahkan suatu permasalahan ke dalam bahasa matematika dengan menggunakan persamaan atau fungsi. Banyak peneliti yang menggunakan model matematika, khususnya di bidang matematika terapan untuk digunakan sebagai dasar dalam penelitian yang dilakukan. Misalnya di bidang fluida, model matematika digunakan sebagai dasar dalam menyelesaikan permasalahan numerik pada studi kasus yang diambil. Sehingga dalam menyelesaikan permasalahan tersebut model matematika yang digunakan sebaiknya tidak rumit.

Penelitian ini bertujuan untuk mendapatkan model matematika pada aliran konveksi bebas fluida viskoelastik yang melewati silinder eliptik dengan pengaruh magnetohydrodinamics (MHD. Aliran tersebut bekerja secara konveksi pada aliran fluida viskoelastik, yaitu fluida yang bersifat viscous (kental) dan elastis sehingga mengakibatkan timbulnya gesekan antara fluida dengan permukaan benda dan memicu timbulnya lapisan-lapisan batas. Pada umumnya bentuk konveksi dibagi menjadi dua, yakni konveksi bebas (free convection) dan konveksipaksa (forced convection). Konveksi bebas disebabkan oleh gaya apung (buoyancy forces) yang dihasilkan dari perbedaan massa jenis. Sedangkan konveksi paksa terjadi pada saat fluida dipaksa untuk mengalir di atas permukaan oleh sumber eksternal maupun internal. Sumber eksternal bekerja pada saat fluida mengalir tanpa batasan benda padat atau dengan kata lain fluida mengalir di atas permukaan bidang. Sumber internal bekerja pada saat fluida mengalir di antara benda padat, misalnya mengalir melalui pipa (Kasim, 2014).

Pada pengaplikasian di bidang teknik, banyak peneliti yang melakukan penelitian terhadap jenis-jenis konveksi. Model matematika yang dibangun pada penelitian ini berasal dari pengembangan persamaan kontinuitas, momentum, dan energi. Persamaan teori lapisan batas (boundary layer theory equation) sederhanamerupakan upaya awal untuk menghitung permasalahan tersebut. Selanjutnya, persamaan pembangun yang 
bersifat dimensional tersebut ditransformasikan ke bentuk persamaan dimensional dan dikelompokkan ke dalam persamaan similaritas dengan menggunakan teori lapisan batas dengan pengaruh gaya magnet. Hasil penelitian ini menunjukkan hubungan antara magnetohydrodinamics (MHD) dengan kecepatan dan temperatur pada model matematika yang telah dihasilkan.

\section{METODE PENELITIAN}

\section{Studi Literatur}

Pada bagian ini peneliti melakukan studi literatur terhadap hal-hal yang berkaitan dalam proses penelitian, misalnya literatur mengenai aliran tak tunak, fluida viskoelastik, lapisan batas, silinder eliptik, heat generation, dan hal lain yang berkaitan dalam permasalahan ini.

\section{Pengumpulan data penelitian}

Pada tahap ini dilakukan pengumpulan data dengan cara menentukan variabel-variabel yang berhubungan dengan kecepatan dan temperatur yang terjadi pada aliran fluida. Variabel-variabel yang mempengaruhi pada studi kasus ini adalah sebagai berikut:

a. Skin friction coefficient

$$
C_{f}=\frac{\tau_{w}}{\rho_{m s} U_{m}^{2}}
$$

b. Bilangan Grashoft

$$
G r=\frac{g \beta a q_{w} a^{3}}{k v^{2}}
$$

c. Temperatur dinding

$$
\theta_{W}=\frac{a q_{W}}{k\left(T_{W}-T_{a s}\right)}
$$

d. Parameter viskoelastik

$$
K=\frac{k_{0} G r^{1 / 2}}{\rho a^{2}}
$$

e. Bilangan Prandtl

$$
\operatorname{Pr}=\frac{\nu}{\alpha}
$$

f. Parameter sumber panas (heat generation)

$$
\gamma=\frac{a^{2} Q_{0}}{v C_{p} G r^{1 / 2}}
$$

\section{Pembangunan model matematika}

Pada bagian ini dikaji model matematika pada aliran tak tunak fluida viskoelastik yang melewati silinder eliptik. Setiap model mempunyai karakteristik tertentu.Sehingga untuk mengembangkan model perlu dikaji terlebih dahulu dalam kaitan untuk mendapatkan model yang sesuai dengan yang diharapkan.Model fisik silinder eliptik seperti pada Gambar 1 dan 2.

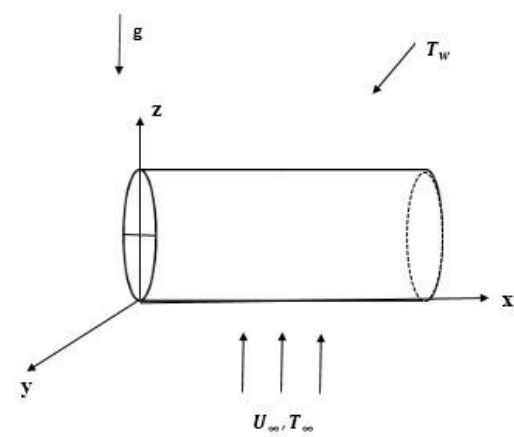

Gambar 1: Model silinder eliptik tiga dimensi

Langkah-langkah dalam membangun model adalah sebagai berikut:

a. Membangun model matematika dari persamaan dimensional, yaitu persamaan kontinuitas, momentum, dan energi;

b. Menentukan kondisi batas (boundary condition) yang digunakan dalam pembangunan model matematika tersebut;

c. Mentransformasikan persamaan dimensional ke persamaan nondimensional yang selanjutnya

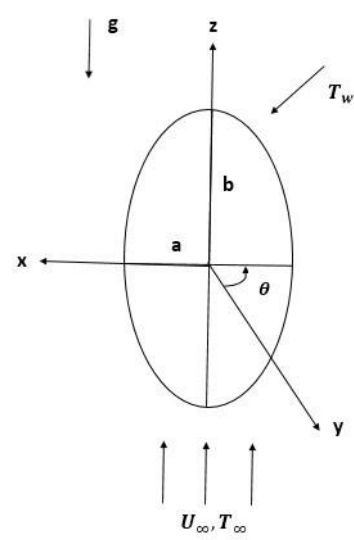

Gambar 2: Model fisik dan sistem koordinat dari aliran yang melalui silinder eliptik tampak dari depan

d. dikelompokkan ke dalam persamaan similaritas dengan menggunakan teori lapisan batas; 
e. Menemukan model matematika dari aliran tak tunak fluida viskoelastik yang melewati silinder eliptik tersebut;

f. Menganalisis hubungan antara parameter Magnetohydrodinamics (MHD) dengan kecepatan dan temperature (heat generation) berdasarkan model matematika yang telah ditemukan.

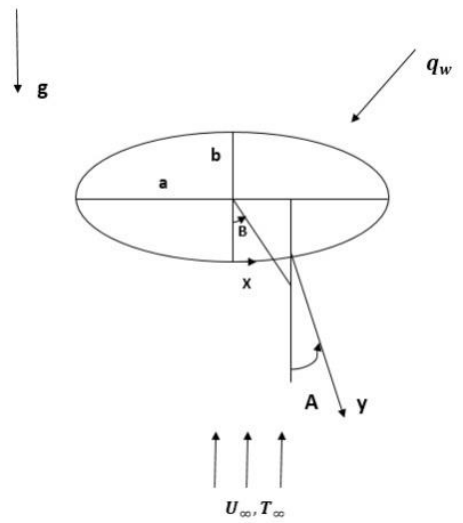

Gambar 3. Model fisik dan sistem koordinat

\section{HASIL DAN PEMBAHASAN}

Pada penelitian ini, persamaan pembangun yang digunakan berasal dari konservasi massa, momentum, dan energi. Persamaan-persamaan tersebut adalah sebagai berikut:

Persamaan kontinuitas:

$$
\frac{\partial u}{\partial x}+\frac{\partial v}{\partial y}=0
$$

Persamaan momentum:

$$
\begin{gathered}
\rho\left(u \frac{\partial u}{\partial x}+v \frac{\partial u}{\partial y}\right)=-\frac{\partial P}{\partial x}+\frac{\partial \tau_{x x}}{\partial x}+\frac{\partial \tau_{y x}}{\partial y}+F_{x} \\
\rho\left(u \frac{\partial v}{\partial x}+v \frac{\partial v}{\partial y}\right)=-\frac{\partial P}{\partial y}+\frac{\partial \tau_{x y}}{\partial x}+\frac{\partial \tau_{y y}}{\partial y}+F_{y}
\end{gathered}
$$

Persamaan energi:

$$
\left(u \frac{\partial T}{\partial x}+v \frac{\partial T}{\partial y}\right)=\alpha \frac{\partial^{2} T}{\partial y^{2}}+\frac{Q_{0}}{\rho C_{p}}\left(T-T_{\mathrm{ss}}\right)
$$

Pada Persamaan (2), pengaruh gaya kental fluida diselesaikan dengan menggunakan tensor Walter-B yang didefinisikan oleh Kasim (2014) sebagai berikut:

$\tau_{i j}=\mu_{0}\left(2 d_{i j}\right)-k_{0}\left(2 \hat{d}_{i j}\right)$

Dengan

$$
\hat{d}_{i j}=V \cdot \nabla\left(d_{i j}\right)-\left(d_{i j}\right)(\nabla V)^{T}-\nabla \cdot V\left(d_{i j}\right)
$$

dan

$d_{i j}=\frac{1}{2}\left[\frac{\partial V_{j}}{\partial x_{i}}+\frac{\partial V_{i}}{\partial x_{j}}\right]$

Dengan menggantikan Persamaan (4) sampai (6) ke Persamaan(2), diperoleh persamaan momentum pada sumbu-x sebagai berikut

$$
\begin{aligned}
& \rho\left(u \frac{\partial u}{\partial x}+v \frac{\partial u}{\partial y}\right)=-\frac{\partial P}{\partial x}+\mu_{0}\left[\frac{\partial^{s} u}{\partial x^{2}}+\frac{\partial^{2} u}{\partial y^{2}}\right]- \\
& k_{0}\left[u\left(\frac{\partial^{\mathrm{a}} u}{\partial x^{\mathrm{a}}}+\frac{\partial^{\mathrm{a}} u}{\partial x \partial y^{2}}\right)+v\left(\frac{\partial^{\mathrm{a}} u}{\partial x^{2} \partial y}+\frac{\partial^{\mathrm{a}} u}{\partial y^{\mathrm{a}}}\right)-\right. \\
& \frac{\partial u}{\partial y}\left(\frac{\partial^{2} u}{\partial x \partial y}+\frac{\partial^{2} v}{\partial x^{2}}\right)-2 \frac{\partial v}{\partial x} \frac{\partial^{2} u}{\partial x \partial y}- \\
& \left.\frac{\partial u}{\partial x}\left(3 \frac{\partial^{2} u}{\partial x^{2}}-\frac{\partial^{2} u}{\partial y^{2}}\right)\right]+F_{x}
\end{aligned}
$$

Dan persamaan momentum pada sumbu-y:

$$
\begin{aligned}
& \rho\left(u \frac{\partial v}{\partial x}+v \frac{\partial v}{\partial y}\right)=-\frac{\partial P}{\partial y}+\mu_{0}\left[\frac{\partial^{z} v}{\partial x^{2}}+\frac{\partial^{z} v}{\partial y^{2}}\right]- \\
& k_{0}\left[u\left(\frac{\partial^{\mathrm{a}} v}{\partial x^{\mathrm{a}}}+\frac{\partial^{\mathrm{a}} v}{\partial x \partial y^{2}}\right)+v\left(\frac{\partial^{\mathrm{a}} v}{\partial x^{2} \partial y}+\frac{\partial^{\mathrm{a}} v}{\partial y^{\mathrm{a}}}\right)+\right. \\
& \frac{\partial u}{\partial x}\left(3 \frac{\partial^{2} v}{\partial y^{2}}-\frac{\partial^{2} v}{\partial x^{2}}\right)-\frac{\partial v}{\partial x}\left(\frac{\partial^{2} v}{\partial x \partial y}+\frac{\partial^{2} u}{\partial y^{2}}\right)- \\
& \left.2 \frac{\partial u}{\partial y} \frac{\partial^{2} v}{\partial x \partial y}\right]+F_{y}
\end{aligned}
$$

Pada kasus ini, aliran fluida dipengaruhi oleh gaya yang bekerja pada fluida. Sehingga, gaya yang bekerja pada fluida $\boldsymbol{F}=\left(F_{x}, F_{y}, 0\right)$ didefinisikan sebagai berikut:

$\mathbf{F}=\rho \mathbf{g}+\mathbf{J} \times \mathbf{B}+\frac{\mu_{0}}{K} \mathbf{V}$

dengan:

g: gravitasi

J : kerapatan arus listrik

$\mathbf{B}$ : gaya magnet $\left(\mathbf{B}=\mathbf{B}_{\mathbf{0}}+b\right)$

$K$ : permeabilitas

V : komponen kecepatan fluida

Menurut Hukum Ohm, kerapatan arus listrik didefinisikan sebagai berikut:

$\mathbf{J}=\sigma(\mathbf{E}+\mathbf{V} \times \mathbf{B})$

dengan:

$\sigma$ : konduktivitas elektrik pada fluida

E : medan listrik 
$\mathbf{B}=\mathbf{B}_{0}+b \quad, \quad$ dengan $\quad \mathbf{B}_{0}=\left(0,0, B_{0}\right)$ merupakan medan magnet pada fluida

Dalam kasus yang terjadi pada penelitian ini, medan listrik dan medan magnet yang terinduksi diabaikan. Hal tersebut disebabkan karena bilangan Reynold magnetik yang diambil sangat kecil. Sehingga $\mathbf{E} \approx 0$ dan $b \approx 0$. Sehingga Persamaan (10) dapat ditulis:

$\mathbf{J}=\sigma\left(\mathbf{V} \times \mathbf{B}_{0}\right)$

Selanjutnya ganti Persamaan (11) ke Persamaan (9), maka didapatkan persamaan berikut:

$\mathbf{F}=\rho \mathbf{g}+\sigma\left(\mathbf{V} \times \mathbf{B}_{0}\right) \times \mathbf{B}+\frac{\mu_{0}}{K}\left(-u_{s}-v_{x} 0\right)$

dengan:

$\left(\mathbf{V} \times \mathbf{B}_{0}\right) \times \mathbf{B}_{0}=\left|\begin{array}{ccc}i & j & k \\ u & v & 0 \\ 0 & 0 & B_{0}\end{array}\right| \times \mathbf{B}_{0}$

Hasil perhitungan Persamaan (13) diperoleh:

$\left(\mathbf{V} \times \mathbf{B}_{0}\right) \times \mathbf{B}_{0}=\left(-u B_{0, v}^{2}-v B_{0,0}^{2} 0\right)$

sehingga Persamaan (12) menjadi:

$\mathbf{F}=\rho \mathbf{g}+\sigma\left(-u B_{0 v}^{2}-v B_{0 x}^{2} 0\right) \times \mathbf{B}$

Pada aliran dua dimensi, gaya gravitasi didefinisikan dengan $\mathbf{g}=\left(-\mathrm{g}_{x},-g_{y}, 0\right)$. Sehingga Persamaan (7) dapat ditulis sebagai berikut:

$\rho\left(u \frac{\partial u}{\partial x}+v \frac{\partial u}{\partial y}\right)=-\frac{\partial P}{\partial x}+\mu_{0}\left[\frac{\partial^{2} u}{\partial x^{2}}+\frac{\partial^{2} u}{\partial y^{2}}\right]-$

$k_{0}\left[u\left(\frac{\partial^{\mathrm{a}} u}{\partial x^{\mathrm{a}}}+\frac{\partial^{\mathrm{a}} u}{\partial x \partial y^{2}}\right)+v\left(\frac{\partial^{\mathrm{a}} u}{\partial x^{2} \partial y}+\frac{\partial^{\mathrm{a}} u}{\partial y^{\mathrm{a}}}\right)-\right.$

$\frac{\partial u}{\partial y}\left(\frac{\partial^{2} u}{\partial x \partial y}+\frac{\partial^{2} v}{\partial x^{2}}\right)-2 \frac{\partial v}{\partial x} \frac{\partial^{2} u}{\partial x \partial y}-$

$\left.\frac{\partial u}{\partial x}\left(3 \frac{\partial^{2} u}{\partial x^{2}}-\frac{\partial^{2} u}{\partial y^{2}}\right)\right]-g_{x}-\sigma u B_{0}^{2}$

dan Persamaan (8) dapat ditulis sebagai berikut:

$\rho\left(u \frac{\partial v}{\partial x}+v \frac{\partial v}{\partial y}\right)=-\frac{\partial P}{\partial y}+\mu_{0}\left[\frac{\partial^{2} v}{\partial x^{2}}+\frac{\partial^{2} v}{\partial y^{2}}\right]-$

$k_{0}\left[u\left(\frac{\partial^{\mathrm{a}} v}{\partial x^{a}}+\frac{\partial^{\mathrm{a}} v}{\partial x \partial y^{2}}\right)+v\left(\frac{\partial^{\mathrm{a}} v}{\partial x^{2} \partial y}+\frac{\partial^{\mathrm{a}} v}{\partial y^{a}}\right)+\right.$

$\frac{\partial u}{\partial x}\left(3 \frac{\partial^{2} v}{\partial y^{2}}-\frac{\partial^{2} v}{\partial x^{2}}\right)-\frac{\partial v}{\partial x}\left(\frac{\partial^{2} v}{\partial x \partial y}+\frac{\partial^{2} u}{\partial y^{2}}\right)-$ $\left.2 \frac{\partial u}{\partial y} \frac{\partial^{2} v}{\partial x \partial y}\right]-g_{x}-\sigma v B_{0}^{2}$

Persamaan (16) dan (17) direduksi ke bentuk persamaan yang lebih sederhana untuk menghasilkan persamaan pendekatan atau yang disebut dengan persamaan lapisan batas (Bejan, 2004). Teori lapisan batas yang digunakan dalam proses penyederhanaan diukur ke dalam bentuk unit 1 dan $\Delta$ sebagai berikut (Ozisik, 1985):

$u \sim 1, x \sim 1, v \sim \Delta, y \sim \Delta, \frac{k_{0}}{\rho} \sim \Delta^{2}, \frac{\mu_{0}}{\rho} \sim \Delta^{2}$,

$g \sim 1, \sigma \sim \frac{1}{\Delta^{2}}, B_{0}^{2} \sim \Delta^{2}$

Sehingga didapat persamaan momentum sumbu $x$ sebagai berikut:

$u \frac{\partial u}{\partial x}+v \frac{\partial u}{\partial y}=-\frac{1}{\rho} \frac{\partial P}{\partial x}+v\left(\frac{\partial^{2} u}{\partial y^{2}}\right)-$

$\frac{k_{0}}{\rho}\left[u \frac{\partial^{2} u}{\partial x \partial y^{2}}+v \frac{\partial^{\mathrm{a}} u}{\partial y^{2}}-\frac{\partial u}{\partial y} \frac{\partial^{2} u}{\partial x \partial y}+\frac{\partial u}{\partial x} \frac{\partial^{2} u}{\partial y^{2}}\right]-$

$g_{x}-\frac{1}{\rho} \sigma u B_{0}^{2}$

Dengan $\boldsymbol{v}=\frac{\mu_{0}}{\rho}$ adalah viskositas kinematik.

Sedangkan untuk persamaan momentum sumbu $y$ diabaikan karena pada pendekatan menggunakan teori lapisan batas menunjukkan bahwa persamaan momentum sumbu $y$ bersifat konstan di seluruh lapisan batas.

Pada kasus ini, pengaruh aliran konveksi mengakibatkan tekanan $P$ didefinisikan sebagai kombinasi dari tekanan hidrostatis $\left(P_{h}\right)$ dan tekanan dinamis $\left(P_{d}\right)$, sehingga dapat ditulis sebagai berikut:

$P=P_{h}+P_{d}$

Tekanan hidrostatis merupakan tekanan pada medium tak bergerak, sehingga besar gravitasi yang diberikan

$$
\nabla P_{h}=\rho_{\infty} g .
$$

dengan $\rho_{\infty}$ adalah densitas fluida. Oleh karena aliran fluida bergerak ke atas, yaitu berlawanan dengan $g$, maka didefinisikan:

$\frac{\partial P_{h}}{\partial x}=-\rho_{\infty} g$

Boussinesq dan teori lapisan batas, didefinisikan

(Cheng, 2012):

$g_{x}=-g \sin A$

dengan 
$\sin A=\frac{b}{a} \frac{\sin B}{\left(1-e^{2} \sin ^{2} B\right)^{1 / 2}}$

Sehingga didapatkan persamaan kontinuitas, momentum, dan energi sebagai berikut:

Persamaan kontinuitas:

$\frac{\partial \bar{u}}{\partial \bar{x}}+\frac{\partial \bar{v}}{\partial \bar{y}}=0$

Persamaan Momentum

$$
\begin{aligned}
& \bar{u} \frac{\partial \pi}{\partial x}+\bar{v} \frac{\partial u}{\partial y}=v\left[\frac{\partial^{2} u}{\partial y^{2}}\right]+g \beta\left(\bar{T}-\bar{T}_{s=}\right) \sin A- \\
& \frac{k_{0}}{\rho}\left[\bar{u}\left(\frac{\partial^{\mathrm{a}} \bar{u}}{\partial \bar{x} \partial \bar{y}^{2}}\right)+\bar{v} \frac{\partial^{\mathrm{a}} \bar{u}}{\partial \bar{y}^{\mathrm{a}}}-\right. \\
& \left.\frac{\partial \bar{u}}{\partial \bar{y}}\left(\frac{\partial^{2} \bar{u}}{\partial \bar{y} \partial \bar{x}}\right)+\frac{\partial \bar{u}}{\partial \bar{x}}\left(\frac{\partial^{2} \bar{u}}{\partial \bar{y}^{2}}\right)\right]- \\
& \frac{1}{\rho} \sigma B_{0}^{2}\left(\bar{u}-\bar{u}_{\theta}\right)
\end{aligned}
$$

Persamaan energi:

$\left(\bar{u} \frac{\partial \bar{T}}{\partial \bar{x}}+\bar{v} \frac{\partial \bar{T}}{\partial \bar{y}}\right)=\alpha \frac{\partial^{2} \bar{T}}{\partial \bar{y}^{2}}+\frac{Q_{0}}{\rho C_{p}}\left(\bar{T}-\bar{T}_{\mathrm{sz}}\right)$

Dengan

batas $\bar{u}=\bar{v}=0, \frac{\partial \bar{y}}{\partial \bar{y}}=-\frac{q_{\mathrm{w}}}{k}$ on $\bar{y}=0$

$\bar{u}=0, \quad \frac{\partial \bar{u}}{\partial \bar{y}}=0, \quad \bar{T}=\bar{T}_{s e}$ as $y \rightarrow \infty$

kondisi

Diberikan variabel- non-dimensional berikut ini (Kasim, 2014):

$$
\begin{aligned}
& v=\frac{a}{v} G r^{-1 / 4} v_{v}, \theta=\left(T-T_{\mathrm{w}}\right) /\left(q_{w} a / k\right) \\
& u_{\theta}=\frac{u_{\theta}}{\bar{x}} U_{\mathrm{wo}}, \quad x=\frac{x}{a}, \\
& y=G r^{1 / 4}\left(\frac{y}{a}\right), u=\frac{a}{v} G r^{-1 / 2} \bar{u}(21)
\end{aligned}
$$

Dengan menggantikan Persamaan (21) ke Persamaan (18) sampai (20), diperoleh persamaan non-dimensional sebagai berikut: Persamaan massa:

$\frac{\partial u}{\partial x}+\frac{\partial v}{\partial y}=0$

Persamaan momentum:

$u \frac{\partial u}{\partial x}+v \frac{\partial u}{\partial y}=\frac{\partial^{2} u}{\partial y^{2}}-K\left[\frac{\partial}{\partial x}\left(u \frac{\partial^{2} u}{\partial y^{2}}\right)+\right.$

$\left.v \frac{\partial^{u} u}{\partial y^{3}}-\frac{\partial u}{\partial y} \frac{\partial^{z} u}{\partial y \partial x}\right]-M\left(u-u_{\varepsilon}\right)-\theta \sin A$

Persamaan energi:

$u \frac{\partial \theta}{\partial x}+v \frac{\partial \theta}{\partial y}=\frac{1}{P r} \frac{\partial^{2} \theta}{\partial y^{2}}+\gamma \theta$

Dengan kondisi batas:

$u=v=0, \theta^{\prime}=-1$ on $y=0$ $u=0, \frac{\partial u}{\partial y}=0, \theta=0 \quad$ as $y \rightarrow \infty$

Dan didefinisikan:

$\operatorname{Pr}=\frac{v}{\alpha}$

$K=\frac{k_{0} G r^{1 / 2}}{\rho a^{2}} \quad$ (Parameter Viskoelastik)

$\gamma=\frac{a^{2} Q_{0}}{v C_{p} G r^{1 / 2}} \quad$ (Parameter Sumber Panas)

$M=\frac{\sigma B_{0} a}{\rho U_{\infty}} \quad$ (Parameter Magnetik)

Untuk menyelesaikan Persamaan (22) sampai (24) dan dengan memperhatikan kondisi batas pada Persamaan (25), serta mengasumsikan $u_{e}(x)=\sin x$ maka diasumsikan (Kasim, 2014):

$\psi=x f(x, y), \quad \theta=\theta(x, y)$

dengan $\psi$ merupakan fungsi aliran yang didefinisikan:

$u=\frac{\partial \psi}{\partial y}, \quad v=-\frac{\partial \psi}{\partial x}$

Pada titik stagnasi terendah silinder, $x \approx 0$, diperoleh persamaan diferensial biasa dari Persamaan (23) dan (24) sebagai berikut: $f^{s t s}+f f^{t s}-\left(f^{t}\right)^{2}+\theta \sin A+K\left(2 f^{\prime} f^{f s t}-\right.$ $\left.f f^{(4)}-\left(f^{t 5}\right)^{2}\right)-M\left(f^{\prime}-1\right)=0$

$\frac{1}{P r} \theta^{r y}+f \theta^{y}+\gamma \theta=0$

Dengan kondisi batas:

$f(0)=f^{\prime \prime}(0)=0, \quad \theta^{\prime}(0)=-1$

$f^{\prime \prime}(\infty)=0, \quad f^{n s}(\infty)=0, \quad \theta(\infty)=0$

\section{KESIMPULAN}

Berdasarkan hasil dan pembahasan yang telah dilakukan sebelumnya, maka diperoleh kesimpulan bahwa hubungan antara parameter magnetohydrodinamics (MHD) dengan kecepatan dan temperatur pada model matematika yang telah dihasilkan adalah semakin besar nilai dari parameter magnetohydrodinamics (MHD), semakin besar pula nilai dari kecepatan dan temperatur yang dihasilkan. Atau dengan kata lain, parameter magnetohydrodinamics (MHD) berbanding lurus dengan besar kecepatan dan temperatur.

\section{UCAPAN TERIMA KASIH}

Ucapan terima kasih penulis sampaikan kepada Universitas PGRI Adi Buana Surabaya, khususnya program studi 
pendidikan matematika, atas dukungan yang telah diberikan kepada penulis selama penulis mengerjakan penelitian ini.

\section{DAFTAR PUSTAKA}

Bejan. 2004. Convection Heat Transfer. John Wiley. New York.

Cheng, C.Y. (2012), "Free Convection Boundary Layer Flow Over a Horizontal Cylinder of Elliptic Cross Section in Porous Media Saturted by a Nanofluid",

International Communications in Heat and Mass Transfer 39, 1-4:931-936.

D’Alessio, S.J.D. dan Perera, R.N. (2009), "Unsteady Free Convection From Elliptic Cylinders at Large Grashof Numbers", International Journal of Heat and Mass Transfer 52,1-11:59405953.

Ghasemi, E., Soleimani, B., dan Bararnia, H. (2012), "Natural Convection Between a Circular Enclosure and Elliptic Cylinder Using Control Volume Based Finite Element Method", International Communications in Heat and Mass Transfer 39,1-2:1035-1044.

Hoffman, K.A. dan Chiang, S.T. (2000), Fourth Edition Computational FluidDynamics Volume I, Engineering Education System. USA.

Kasim, A.R.M. (2014), Convective Boundary Layer Flow of Viscouselastic Fluid, Universiti Technology Malaysia, Malaysia.

Lienhard, J.H. (2008), A Heat Transfer Textbook Third Edition, Phlogiston Press, Cambridge, Massachussetts, USA.

Long, C. dan Sayma, N. (2009), Heat Transfer 1st Edition.

Marinet, M.F. dan Tardu, S. (2009), Convective Heat Transfer Solved Problems, ISTE Ltd, UK.

Munson, B.R., Young, D.F., dan Okiishi, T.H. (2002), Fourth Edition Fundamentalsof Fluid Mechanics, Lowa State University, USA.
Ozisik, M.N. 1985. Heat Transfer: A Basic Approach. McGraw-Hill. New York.Potter, M.C., Wiggert, D.C., dan Ramadan,B.H. (2012), Mechanics of Fluids Fourth

Edition, Cengage Learning, USA.

Potter, M.C., Wiggert, D.C., dan Ramadan,B.H. (2008), Schaum's OutlineMekanika Fluida, Erlangga, Jakarta. 69

Sarif, N.M., Salleh, M.Z., Tahar, R.M., dan Nazar, R. (2013), "Numerical Solution of the Free Convection Boundary Layer Flow over a Horizontal Circular Cylinder with Convective Boundary Conditions", Universiti Malaysia Pahang,Malaysia.

Sen, M. (1996), Lecture Notes on Intermediate Fluid Mechanics, University of Notre Dame.

Versteg, H.K. dan Malalasekera (1995), An Introduction to Computational FluidDynamics The Finite Volume Method, Longman Scientific Technical, England.

Widodo, B., Fatahillah, A., Rahayuningsih, T. (2011), "Mathematical Modelling and Numerical Solution of Iron Corrosion Problem Based on Condensation Chemical Properties", Australian Journal of Basic and Applied Sciences", 5(1), pp. 79-86.

Widodo, B., Wen, X., Ingham, D.B, (1997), "The Free Surface Fluid Flow inan Arbitrary Shaped in a Channel", Journal of Engineering Analysis with Boundary Element, Vol. 19, PP.299308.

Siswono, G.O. (2015). Analisa Aliran Konveksi Campuran Pada FluidaViskoelastikMagnetohydrodyna mics

(Mhd)

Yang Melewati Silinder Sirkular Berpori [Tesis]. Surabaya:Institut Teknologi Sepuluh Nopember. 